\title{
TEMPORAL DISCRIMINATION IN JAPANESE MONKEYS ${ }^{1}$
}

\author{
MASATO ITO \\ Osaka City University \\ AND \\ TOSHIO ASANO ${ }^{2}$ \\ Primate Research Institute, Kyoto University
}

\begin{abstract}
Temporal discrimination in Japanese monkeys was examined adopting a psychophysical method, originally developed in the study of pigeons, and modified in the present study by adding a sample duration prior to each trial in order to make the procedure close to the method of reproduction in human psychophysics. When only one sample duration was employed within a session, the subjects' performance was independent of the sample duration and was based simply on a differential reinforcement of latencies. Their performance was well described by a power function and revealed better temporal discrimination than that shown by pigeons. When two different sample durations were presented systematically within a session, the sample durations obtained some degree of discriminative control, although some interaction between the two sample durations occurred.
\end{abstract}

The study of temporal discrimination has been classified into two categories in terms of its dependent variable (Catania, 1970 ; Staddon, 1972). One measures a change in rate or directions of responding occasioned by a preceding temporal stimulus (Cowles \& Finan, 1941; Heron, 1949 ; Reynolds \& Catania, 1962 ; Behar, 1963; Stubbs, 1968). The other measures temporally spaced responding which is maintained directly by temporal properties of a reinforcement schedule, e.g., a differential reinforcement of low rate

1 This study was conducted as a cooperative research in Primate Research Institute, Kyoto University.

2 The authors are grateful to Dr. T. Ogawa, Dr. K. Murofushi and Dr. E. Fantino for their useful suggestions and encouragements during the experiment. The assistance of Mr. J. Nagumo is gratefully acknowledged.

Reprints may be obtained from Masato Ito, Department of Psychology, Osaka City University, 459, Sugimoto-cho, Sumiyoshi-ku, Osaka 558 Japan.
(DRL), long latency (DRLL) or response duration schedule (Wilson \& Keller, 1953 ; Catania, 1970 ; Platt, Kuch, \& Bitgood, 1973).

Most of these studies are concerned in the establishment of a psychophysical method for the study of temporal discrimination in animals. For example, Catania (1970) developed a DRLL schedule as a scaling procedure in pigeons. In a DRLL schedule, an external stimulus, e.g., a key light, is presented on each trial. The first response to the lit key is differentially reinforced according to the response latency. When the latency exceeds a required minimum latency $(t)$ the response is reinforced, whereas the response is extinguished when the latency does not exceed t. Catania found that pigeon's mean latency under a DRLL schedule can be well described as a power function of a required minimum latency $(t)$. Further, showing that the values of the exponent of the power function obtained were less than 1.0, he pointed out the similarity of 
animal performances to human temporal judgments measured under the method of reproduction. On the basis of the similarity to human performance, it was assumed that a DRLL schedule could be an effective scaling procedure in animal subects.

While the data suggest the similarity of animal performances to human temporal judgments, there are a few procedural differences between the method of reproduction and DRLL schedule. An important procedural difference is that the latencies in previous trials were regarded as sample durations in Catania's procedure, while an explicit sample duration precedes each performance of the subject in the method of reproduction (cf. Treisman, 1963).

With this procedural difference in mind, the present experiments were designed to examine a modified DRLL schedule in which a sample duration was presented prior to each performance of Japanese monkeys.

\section{EXPERIMENT 1}

\section{Method}

Subjects. Two adult male Japanese monkeys (Macaca fuscata fuscata), housed individually, were maintained at approximately $90 \%$ of their free-feeding body weights throughout the experiment $(10.2 \mathrm{~kg}$ for $\mathrm{S}-1 ; 13.0 \mathrm{~kg}$ for S-40). The subjects had experienced a variable interval $2 \mathrm{~min}$ (VI 2) schedule for two months before the present experiment.

Apparatus. An experimental chamber $(75 \times$ $75 \times 75 \mathrm{~cm}$ ) with a lever and two response panels was used. Two circular response panels $(6.4 \mathrm{~cm}$ in diameter) were mounted $14 \mathrm{~cm}$ apart, center to center, on the front wall of the chamber at $45 \mathrm{~cm}$ above the floor. The lever, intruded $2 \mathrm{~cm}$ into the chamber, located $10 \mathrm{~cm}$ below the response panels at the center of the front wall. A force of $20 \mathrm{~g}(0.2 \mathrm{~N})$ was required to operate the lever and response panels. Each response panel could be illuminated from behind by a DC $24 \mathrm{~V}$ red, blue or yel- low bulb. A food cup was mounted, $20 \mathrm{~cm}$ below the lever, on the front wall and was illuminated by a DC $24 \mathrm{~V}$ white bulb for $2 \mathrm{sec}$ each time a grain of soybean (about $0.37 \mathrm{~g}$ ) was delivered into the cup by means of a soybean dispenser (TOSOKU).

A PDP-8/F minicomputer (DEC), located in an adjacent room, controlled the experiment and recorded latencies. White noise masked extraneous sounds.

Procedure. The subjects were trained initially to press a lever on a continuous reinforcement (CRF) schedule for three sessions. Then, another three sessions followed in which a lever press produced a blue light on the right panel, and a response to the right panel terminated the blue light and produced a reinforcer. Responses to the left panel during this phase had no scheduled consequences.

After the preliminary training, a modified DRLL schedule was introduced. A press on the lever initiated a trial with a red light on the left panel. After a sample duration ( $t$ ) had passed, the red light was turned off and the right panel was lit with a blue light. If a response to the red panel had occurred during the sample duration, the trial was cancelled immediately and another press of the lever was required to restart the trial. A response to the blue light before another $t$ sec (i.e., the same duration as the sample) had elapsed turned the blue light to a yellow light. The yellow light (Error signal) lasted $2 \mathrm{sec}$ during which the subjects could not initiate the next trial by pressing the lever. If the latency of the response to the blue light exceeded $t \mathrm{sec}$, the food cup was illuminated and a reinforcer was delivered.

The value of $t$ that determined the sample duration and the minimum reinforced latency was $0.5,1.0,3.0,5.0,7.0$, and $10.0 \mathrm{sec}$, respectively. Only one value of $t$ was used within a session. Changes in the value of $t$ were made in ascending order when performance appeared stable according to visual inspection of daily variation in mean latency. Each daily session consisted of 100 presentations of the blue light (100 trials). Since each trial was initiated by the subject, there was no predetermined inter- 
TABLE 1

Number of sessions, mean latencies $(T)$ and coefficients of variation $(S D / T)$

based on the last two sessions of each value of $t$

\begin{tabular}{c|ccc|ccc}
\hline Subject & \multicolumn{3}{|c|}{$\mathrm{S}-40$} & \multicolumn{3}{c}{$\mathrm{S}-1$} \\
\hline $\mathrm{t}(\mathrm{sec})$ & Sessions & $\mathrm{T}(\mathrm{sec})$ & $S D / \mathrm{T}$ & Sessions & $\mathrm{T}(\mathrm{sec})$ & $S D / \mathrm{T}$ \\
\hline 0.5 & 6 & & & 6 & & \\
1.0 & 13 & 1.30 & 0.19 & 5 & 1.30 & 0.20 \\
3.0 & 17 & 3.53 & 0.20 & 15 & 3.51 & 0.17 \\
5.0 & 15 & 5.53 & 0.19 & 10 & 6.19 & 0.17 \\
7.0 & 9 & 8.51 & 0.13 & 12 & 8.53 & 0.14 \\
10.0 & 15 & 11.18 & 0.17 & 22 & 11.66 & 0.16 \\
\hline & & 10.01 & $0.18 \mathrm{a}$ & & & \\
5.0 & & 11.05 & $0.20 \mathrm{~b}$ & & & \\
(and) & 8 & 11.01 & $0.26 \mathrm{a}$ & & & \\
10.0 & & 10.02 & $0.12 \mathrm{~b}$ & & &
\end{tabular}

a: The first session of the probe test.

b: The final session of the probe test.

trial-interval. The session time varied with the value of $t$, from about $6 \mathrm{~min}$ when the value of $t$ equaled $0.5 \mathrm{sec}_{\text {, }}$ to about $45 \mathrm{~min}$ when the value of $t$ equaled $10.0 \mathrm{sec}$.

After the value of $t$ had reached $10.0 \mathrm{sec}$, probe test sessions were introduced employing two different values of $t$ in order to examine whether or not the sample duration did exert control over the spaced responding, and also to examine when the subject did begin timing; was it at the onset of the red light, or the blue light? The values of $t$ during those test sessions were 5.0 and $10.0 \mathrm{sec}$. These two values of $\mathrm{t}$ were presented randomly according to a Gellerman sequence within a session. Only one subject (S-40) served in the probe test.

The unit of measurement for latency was 10 msec. Data of the subject's performance were punched out on the paper-tape, and processed later by a PDP-12.

\section{Results and Discussion}

Mean latencies $(\mathrm{T})$ and coefficients of variation (standard deviation relative to mean latency), based on the last two sessions, are presented in Table 1 for each value of the minimum reinforced latency ( $t$ ) except $t$ equal to 0.5 sec. Data at $t$ equal to $0.5 \mathrm{sec}$ are lost due to an error in the minicomputer program. The result of the probe test sessions on $\mathrm{S}-40$ is shown in the lower part of Table 1.

The mean latencies of both monkeys at each value of $t$ were very similar. It is shown that for all values of $t$, the mean latency slightly exceeds the value of $t$, indicating that the mean latencies shown by both monkeys well match the minimum reinforced latency $(t)$. The variation in latencies within a session was not systematic in both monkeys.

Latency distributions in class intervals of one-fifth of $t$ are presented for both monkeys in Fig. 1 in the same manner as Catania (1970). Filled portions show unreinforced latencies and unfilled portions show reinforced latencies. Latency distributions in Fig. 1 were based on the last two sessions and presented for each value of $t$. Most unreinforced latencies were included in the class interval of $0.8 \mathrm{t}$ to $t$ and the peak of distribution was at a class interval of $t$ to $1.2 \mathrm{t}$ except for the value of $t$ equal to $5.0 \mathrm{sec}$ in $\mathrm{S}-40$. In the case of S-1, there were a few latencies shorter than $0.2 \mathrm{t}$ sec when the value of $t$ 
was set at 5.0 or $7.0 \mathrm{sec}$.

Coefficients of variation varied with the value of $t$, ranging from 0.20 to 0.13 . The smallest coefficient of variation was found when the value of $t$ equaled $7.0 \mathrm{sec}$ for both monkeys ; 0.13 for S-40, 0.14 for S-1, respectively.

The performances of both monkeys are described by power functions in Fig. 2, where mean latencies are plotted against each value of $t$ in logarithmic coordinates. The solid line represents the locus of perfect matching between mean latency $(T)$ and the minimum reinforced latency $(t)$. The dashed line indicates a least-square fit of the obtained data to the power function. The fit yielded a function $T=$ $1.22 \mathrm{t}^{0.97}$ for $\mathrm{S}-40$, and $\mathrm{T}=1.18 \mathrm{t}^{\mathrm{t} .01}$ for S-1. The pooled data of both monkeys are described by $T=1.2 t^{1.0}$.

These data are inconsistent with Cat-

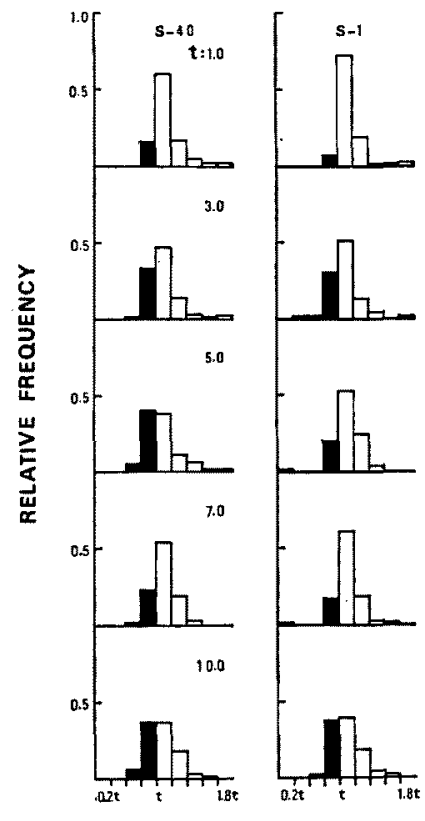

LATENCY

FIG. 1. Latency distributions in class intervals of one-fifth of the minimum reinforced latency $(t)$. Filled portions show the unreinforced latencies. Unfilled portions show the reinforced latencies. The data are based on last two sessions of each value of $t$. ania's suggestion that the values of the exponent of a power function obtained under temporally defined schedules are less than 1.0. However, the fact that the performance of each subject can be described by a power function is consistent with the findings in previous studies (Catania, 1970 ; Platt, et al., 1973).

Data from the probe test on S-40 are shown in the lower part of Table 1. The upper column (a) for each value of $t$ represents the mean latency based on the first test session. The lower column (b) represents the mean latency based on the final test session.

Mean latencies of the test sessions were consistently about $10 \mathrm{sec}$ regardless of the value of $t$ (either 5.0 or $10.0 \mathrm{sec}$ ). The fact that the mean latency was about $10 \mathrm{sec}$ when the value of $t$ was equal to $5.0 \mathrm{sec}$ reveals that the subject did start timing from the onset of the blue light.

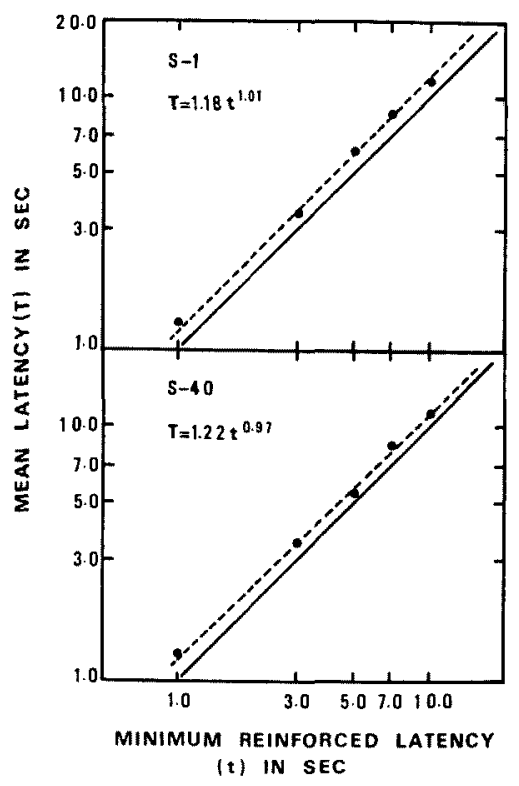

FIG. 2. Mean latencies (T) plotted against each value of the minimum reinforced latency $(t)$ in logarithmic coordinates. Each value is based on last two sessions. The solid line represents the perfect matching of $T$ to the value of $t$. The dashed line indicates least-square fits of power functions to $T$. 
Had timing begun with the onset of the red light in the previous sessions $(t=10.0)$, the latency in the 5 sec-trial should have shown a value around $15 \mathrm{sec}$.

However, the sample duration in these test sessions did not exert control over the spaced responding. Therefore, the subject might have ignored the sample duration throughout the experiment, and responded to the blue light in every trial with the latency which had been established in the sessions before the probe test. The lack of control by the sample duration could have resulted from a procedure in which only one value of $t$, therefore only one sample duration, was employed within a session. However, it must be noted that the subject did start timing at the onset of the blue light and emitted spaced responding according to the results of previous trials, even though a sample duration was given just before each performance.

If two or more different values of $t$ are presented more systematically, rather than presented randomly, within a session in order to expose the subject to a systematic change in the rate of reinforcement associated with the length of sample duration, the sample duration may acquire control as a discriminative stimulus for the following spaced responding.

\section{EXPERIMENT 2}

In Experiment 2, an attempt was made to examine whether or not each sample duration exerts control over spaced responding when two different values of $t$ were presented systematically within a session. In addition, the maintenance of spaced responding under a single but longer value of $t$ than in Experiment 1 was examined.

\section{Method}

Subjects and apparatus. The same subjects and apparatus described in Experiment 1 were used.
Procedure. The procedure for subject S-1 remained the same as in Experiment 1, although the value of $t$ was extended to 13,16 , and $30 \mathrm{sec}$.

For subject S-40, a session consisted of 100 trials, divided into 4 blocks of 25 trials each. During a session, the subject was exposed to a pair of $t$ values. The $t$ value in blocks 1 and 3 was always $10 \mathrm{sec}$. An alternative $t$ value was assigned to blocks 2 and 4 . For the first set of sessions, the alternative $t$ value was $5 \mathrm{sec}$; for the next set, it was $20 \mathrm{sec}$; for the last set, it was $30 \mathrm{sec}$. Changes between alternative $t$ values were made when performance appeared stable according to visual inspection of daily variation in mean latency.

\section{Results and Discussion}

Mean latencies $(\mathrm{T})$ and coefficients of variation $(S D / \mathrm{T})$ for each value of the minimum reinforced latency $(\mathrm{t})$ are presented in Table 2. Data were pooled over the last five sessions.

When two different values of $t$, therefore two sample durations, were employed within a session, a differentiation of spaced responding for each value of $t$ was evident in the last two pairs. In the first pair (10 vs. $5 \mathrm{sec}$ ), however, differences in spaced responding for each value of $t$ were not observed. It was found that the mean latency of the $10 \mathrm{sec}$ trials increased as the alternative $t$ value varied from 5 to $30 \mathrm{sec}$. The values of coefficient of variation indicate that the performance during a session was fairly stable.

Figure 3 shows session to session variation in the mean latency. The dashed horizontal lines indicate the minimum reinforced latencies. Filled circles represent mean latency of the $10 \mathrm{sec}$ trials; filled triangles represent mean latency of the trials with an alternative $t$ value. The mean latency of the $10 \mathrm{sec}$ trials increased gradually as the mean latency of the $20 \mathrm{sec}$ trials increased. When the alternative $t$ value changed from 20 to $30 \mathrm{sec}$, however, no conspicuous change in the latency of the $10 \mathrm{sec}$ trials were observed, 
TABLE 2

Number of sessions, mean latencies $(T)$ and coefficients of variation $(S D / T)$ for each value of the minimum reinforced latency $(t)$

\begin{tabular}{|c|c|c|c|c|c|c|c|}
\hline \multirow{2}{*}{$\frac{\text { Subject }}{t(\text { sec })}$} & \multicolumn{3}{|c|}{ S-40 } & \multicolumn{4}{|c|}{ S.1 } \\
\hline & Sessions & $\mathrm{T}(\mathrm{sec})$ & $S D / \mathrm{T}$ & $t(s e c)$ & Sessions & $\mathrm{T}$ (sec) & $S D / \mathrm{T}$ \\
\hline $\begin{array}{r}10.0 \\
5.0\end{array}$ & 5 & $\begin{array}{r}10.18 \\
9.87\end{array}$ & $\begin{array}{l}0.15 \\
0.19\end{array}$ & 13.0 & 29 & 18.67 & 0.17 \\
\hline $\begin{array}{l}10.0 \\
20.0\end{array}$ & 34 & $\begin{array}{l}14.41 \\
22.85\end{array}$ & $\begin{array}{l}0.21 \\
0.18\end{array}$ & 16.0 & 25 & 21.10 & 0.15 \\
\hline $\begin{array}{l}10.0 \\
30.0\end{array}$ & 21 & $\begin{array}{l}15.08 \\
31.36\end{array}$ & $\begin{array}{l}0.23 \\
0.21\end{array}$ & 30.0 & 24 & 34.57 & 0.16 \\
\hline
\end{tabular}

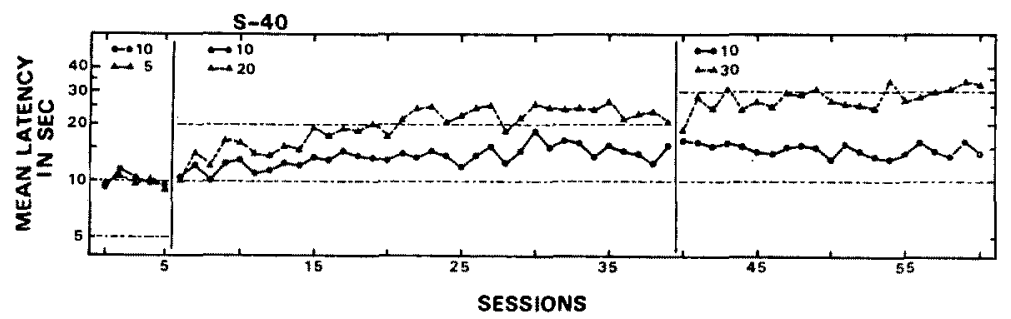

Frc. 3. The session to session variations in the mean latency of S-40, when two different values of $t$ were presented within a session. The dashed horizontal lines show the minimum reinforced latency $(t)$. The ordinate is logarithmic.

despite an increase in the mean latency of the $30 \mathrm{sec}$ trials.

Figure 4 shows latency distributions in
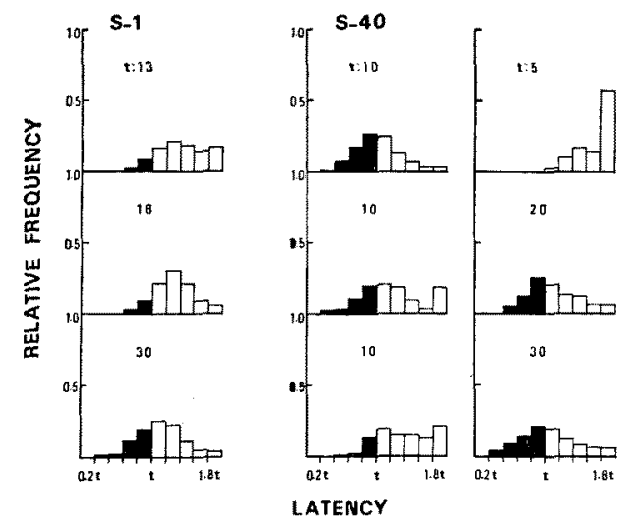

Ftg. 4. Latency distributions in class intervals of one-fifth of the minimum reinforced latency $(t)$ for both monkeys. Filled portions show the unreinforced latencies. Unfilled portions show the reinforced latencies. class intervals of one-fifth of t. Each distribution was based on data presented in Table 2. Filled portions show unreinforced latencies, while unfilled portions show reinforced latencies. Latency distributions in the $10 \mathrm{sec}$ trials shifted to longer class intervals as the alternative $t$ value varied from 5 to $30 \mathrm{sec}$.

Although those results indicate an interaction between the two values of $t$ in a pair, it seems that a differentiation of spaced responding for each value of $t$ was established to some extent under the present procedure.

Table 3 shows latency changes within a session. Data from the last five sessions were pooled, and mean latencies calculated on the last three trials of the 3rd block (10 sec trials) and on the first three trials of the 4th block (alternative $t$ trials). As shown in Table 3 , the mean latency changed immediately when the $t$ value 
TABLE 3

Mean latencies (T) and standard deviation $(S D)$ based on last three trials of the 3rd block and first three trials of the 4th block for each pair of the minimum reinforced latency $(t)$

\begin{tabular}{|c|c|c|c|c|}
\hline \multirow{2}{*}{$\begin{array}{l}\text { Values of } t \\
\text { in pairs } \\
\text { (sec) }\end{array}$} & \multicolumn{2}{|c|}{ 3rd Block } & \multicolumn{2}{|c|}{ 4th Block } \\
\hline & $\mathrm{T}$ & $S D$ & $\mathrm{~T}$ & $S D$ \\
\hline 10 vs. 5 & 11.04 & $(3$. & 10.65 & $(2.59)$ \\
\hline 10 vs. 20 & 12.80 & $(4.39)$ & 19.95 & $(5.60)$ \\
\hline 10 vs. 30 & 14.49 & $(3.83)$ & 31.29 & $(10.48)$ \\
\hline
\end{tabular}

was changed to the alternative $t$ equal to 20 or $30 \mathrm{sec}$. This immediate change in the latency suggests that the sample duration did exert control over spaced responding at least when the alternative $t$ was equal to 20 or $30 \mathrm{sec}$.

The subject S-1 which was exposed further to single $t$ value sessions maintained spaced responding very well even when the value of $t$ equaled $30 \mathrm{sec}$. As shown in Table 2, the mean latency consistently exceeded the minimum reinforced latency. The coefficients of variation indicate that the performance was stable across the values of $t$ employed. Although latency distributions, as shown in Fig. 4, revealed that the portion of reinforced latencies at both $t$ equal to 13 and $16 \mathrm{sec}$ was larger than at $t$ equal to $30 \mathrm{sec}$, the mean latency remained longer than the minimum reinforced latency even when $t$ equaled $30 \mathrm{sec}$, unlike the pigeon's performance in Catania (1970).

\section{General Discussion}

The main purpose of the present study was to examine a modified DRLL schedule as a scaling procedure for monkeys similar to the method of reproduction in human subjects in which the sample duration is presented prior to each performance. Although the performance of monkeys was well maintained under this schedule, the results of the probe test for
S-40 suggested that the sample duration did not exert control over spaced responding when a single value of $t$ was employed within a session. The results of Experiment 2 showed that a differentiation of spaced responding occasioned by the sample duration was established to some extent when two different values of $t$ were presented systematically within a session. The major factor responsible for the establishment of control by the sample duration might be a conspicuous change in the rate of reinforcement associated with a block of trials within a session. For example when the alternative $t$ value was equal to 20 or $30 \mathrm{sec}$, reinforcement rate might abruptly decrease in the 2nd and the 4th block if the subject responded as it had in the preceding block of the $10 \mathrm{sec}$ trials. In order to avoid such reductions in reinforcement rate, the subject had to attend to the sample durations. In this way, the sample durations could acquire discriminative control over spaced responding. This may also be a reason why the sample durations did not exert control in the first pair (10 vs. $5 \mathrm{sec}$ ), whereas they did in the last two pairs.

Although stimulus control by the sample duration was established employing two different values of $t$ within a session, some interaction between two different values of $t$ in a pair appeared. The interaction observed in the present study can be regarded as a case of induction, which is sometimes found in multiple schedules (cf. Reynolds, 1963). In a multiple schedule, induction refers to the case in which the response rate under one stimulus increases (or decreases) corresponding to an increase (or decrease) in response rate under another stimulus. In fact, as shown in Fig. 3, the mean latency for $t$ equal to $10 \mathrm{sec}$ increased with increases in the mean latency for $t$ equal to $20 \mathrm{sec}$. The occurrence of induction observed in Experiment 2 suggests a need for additional experimental operations in order to establish precise control by the sample du- 
rations. In this respect, the adoption of an upper limit to reinforced latency may be useful (Kuch, 1974; Saslow, 1968, 1972).

While control of the sample duration over spaced responding, as suggested above, may be questionable when a single value of $t$ was employed within a session, spaced responding per se was maintained across values of $t$ ranging from 0.5 to $30 \mathrm{sec}$. As shown in Experiment 1, the performance of both monkeys can be described by a power function. The pooled data of S-1 including the data obtained in Experiment 2 were also described by the following function: $T=1.11 \mathrm{t}^{1.0}$ (see Fig. 5).

Gatania (1970) found that the pigeon's performance was described by the power function: $T=1.6 t^{0.8}$. Meanwhile, the present procedure in Experiment 1 and Experiment 2 on S-1 turned out to be close to a simple DRLL schedule, since the subjects ignored the sample duration. However, the values of the exponent (the slope) and coefficient (the vertical displacement) of the power function obtained in the present study on monkeys are different from those obtained with pigeon's. In monkeys, the exponent is closer to 1.0 and the coefficient is smaller than in pigeons. These differences may reflect the differences in the performance of pigeons and monkeys. As shown in Figs. 1 and 4, distributions of the latency were narrower in the case of monkeys than

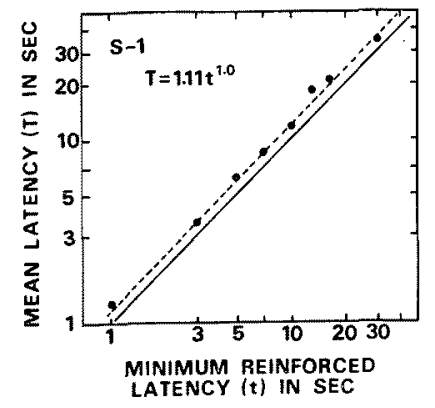

FIG. 5. For the combined data of S-1 in Exp. 1 and 2, Mean latencies ( $T$ ) are plotted by the same manner as in Fig. 2. in pigeons. The peak of the distribution for each value of $t$ fell in the class interval of $t$ to $1.4 t$, whereas in pigeons the peak of the distribution shifted toward longer class intervals as the value of $t$ decreased. The values of the coefficient of variation were less than 0.2 for any value of $t$. In the case of pigeons, however, the coefficient of variation was always larger than 0.2 .

One of the possible accounts for the differences in the performance of pigeons and monkeys is that monkeys may be more sensitive than pigeons to the requirement of reinforcement. Although there are few studies on this matter, the results of the following experiments are suggestive. Gamzu and Schwam (1974), with an automaintenance procedure, demonstrated that a response-reinforcer dependency was necessary to maintain a key-press response of squirrel monkeys. On the other hand, the maintenance of pigeon's key-pecking responses under automaintenance procedure has been demonstrated by several investigators (Williams \& Williams, 1969 ; Herrnstein \& Loveland, 1972 ; Schwartz \& Williams, 1972 ; Hursh, Navarick, \& Fantino, 1974). Hursh, et al., (1974) showed that pigeon's key-pecking responses under an automaintenance procedure were maintained by a reinforcer other than food delivery, e.g., the response-dependent offset of a key light. These findings, therefore, suggest that monkeys may be more sensitive to the response-food delivery relationship than pigeons.

It is also possible to account for the difference in the performance of monkeys and pigeons in terms of procedural differences. The sequence of values of $t$ in the present experiment was an ascending order, whereas both ascending and descending orders were used in the Catania's experiment. As in errorless discrimination (Terrace, 1963), the progressive introduction of values of $t$ from the shorter to the longer one may be favorable to the formation of temporal discrimina- 
tion. These procedural differences may affect the slope (exponent) and the vertical displacement (coefficient) of the power function.

The findings of Experiment 2 may provide a basis for the further investigation of temporal discrimination, and for the effort to establish a procedure corresponding to the method of reproduction in human psychophysics. The results obtained in Experiment 2 suggest that the monkey attended, and responded differentially, to each sample duration. If this is the case, the present procedure may be assumed to be analogous to the method of reproduction in terms of control by the sample durations. However, further attempts to eliminate the interaction between different $t$ values observed in the present study are desirable.

\section{REFERENGES}

BEHAR, I. 1963 A method for scaling in infrahuman species: Time perception in monkeys. Perceptual and Motor Skills, 16, 275-280.

Catania, A. C. 1970 Reinforcement schedules and psychophysical judgments: A study of some temporal properties of behavior. In W. N. Schoenfeld (Ed.), The theory of reinforcement schedules. New York: AppletonCentury-Crofts.

Cowles, J.T., \& Finan, J. L. 1941 An improved method for establishing temporal discrimination in white rats. Fournal of Psychology, 11, 335-342.

GamzU, E., \& Schwam, E. 1974 Autoshaping and automaintenance of a key-press response in squirrel monkeys. Fournal of the Experimental Analysis of Behavior, 21, 361-371.

Heron, W. T. 1949 Time discrimination in the rat. Journal of Comparative and Physiological Psychology, 42, 27-31.

Herrnstein, R.J., \& Loveland, D. H. 1972 Food-avoidance in hungry pigeons and other perplexities. Fournal of the Experimental Analysis of Behavior, 18, 369-383.

Hursh, S. R., Navarick, D. J., \& Fantino, E. 1974 "Automaintenance": The role of reinforcement. Fournal of the Experimental Analysis of Behavior, 21, 117-124.
Kuch, D. O. 1974 Differentiation of press durations with upper and lower limits on reinforced values. Fournal of the Experimental Analysis of Behavior, 22, 275-283.

Platr, J. R., Kuch, D. O., \& Bitgood, S. C. 1973 Rat's lever-press duration as psychophysical judgments of time. Fournal of the Experimental Analysis of Behavior, 19, 239-250.

Reynolds, G. S. 1963 Some limitations on behavioral contrast and induction during successive discrimination. Fournal of the Experimental Analysis of Behavior 6 131-139.

Reynolds, G. S., \& Catanla, A. G. 1962 Temporal discrimination in pigeons. Science, 135, 314-315.

SasLow, C. A. 1968 Operant control of response latency in monkeys: Evidence for a central explanation. Journal of the Experimental Analysis of Behavior, 11, 89-98.

SAsLOW, C.A. 1972 Behavioral definition of minimal reaction time in monkeys. Fournal of the Experimental Analysis of Behavior, 18, 87-106.

Schwartz, B., \& Willtams, D. R. 1972 Two different kinds of key peck in the pigeon: Some properties of responses maintained by negative and positive response-reinforcer contingencies. Fournal of the Experimental Analysis of Behavior, 18, 201-216.

STADDON, J.E.R. 1972 Temporal control and the theory of reinforcement schedules. In R. M. Gilbert \& J. R. Millenson (Eds.), Reinforcement: Behavioral analyses. New York: Academic Press.

StuBbs, A. 1968 The discrimination of stimulus duration by pigeons. Fournal of the Experimental Analysis of Behavior, 11, 223-238.

Terrace, H.S. 1963 Discrimination learning with and without "errors". Fournal of the Experimental Analysis of Behavior, 6, 1-27.

Treisman, M. 1963 Temporal discrimination and the indifference interval: Implications for a model of the "internal clock". Psychological Monographs, 77, (13, Whole No. 576).

Williams, D. R., \& Williams, H. 1969 Automaintenance in the pigeon: Sustained pecking despite contingent non-reinforcement. Journal of the Experimental Analysis of Behavior, 12, 511-520.

Wilson, M. P., \& Keller, F. S. 1953 On the selective reinforcement of spaced responses. Journal of Comparative and Physiological Psychology, 46, 190-193.

(Received Feb. 7, 1977) 